\title{
SEISMIC RISK THROUGH SOCIAL VULNERABILITY: A METHODOLOGICAL PROPOSAL FOR THE EVALUATION OF THE SEISMIC VULNERABILITY ON THE COAST OF ALICANTE, SPAIN
}

\author{
PABLO AZNAR-CRESPO \& ANTONIO ALEDO \\ University Institute of Water and Environmental Sciences, University of Alicante, Spain
}

\begin{abstract}
The province of Alicante (Spain), especially the southern part, is one of the regions with the highest seismic risk in the peninsular territory. The interaction between the high seismic danger and the social vulnerability that characterizes the coast of the province of Alicante implies a significant level of risk. Based on this, this paper criticizes the lack of analytical depth in the field of seismology and seismic risk planning to analyze and evaluate the seismic vulnerability that characterizes a population. In particular, a total lack of social factor has been verified in the evaluation of the seismic vulnerability, as well as an absesnce of a procedural perspective in the construction of the risk. However, an excessively technical seismic risk management has been found, exclusively based on the analysis of the architectural resistance of the buildings. This paper argues the need to rethink the concept of seismic risk in depth, in order to understand it as a socially constructed process. In addition, a specific methodological proposal is made to analyze and evaluate the seismic vulnerability of the municipalities of the Alicante coast in an integrated way. This area is exposed to social and economic phenomena that make them especially sensitive to the effects of seismic movements. In short, this paper claims the need to dispute the hegemony of the technocratic paradigm that dominates the analysis and planning of seismic risk in order to move towards a more integrated and multidisciplinary approach that allows to increase the seismic-social resilience of society and territory.

Keywords: seismic vulnerability, evaluation, social vulnerability, risk, ontology, planning.
\end{abstract}

\section{INTRODUCTION}

Valencian Community, like other geographical points of the Mediterranean area, is one of the Spanish regions with the highest exposure to natural hazards. It is a space of risk, determined by two main factors: 1) climatic-meteorological and geophysical characteristics of its territory, which favor the occasional production of extreme natural phenomena such as droughts, floods, forest fires and earthquakes; and 2) an inadequate occupation and use of the territory, more especially at the coast [1]. The risk has to be understood as an intersection between conditions of high physical-natural danger and a vulnerable socio-demographic structure. In the specific case of seismic risk, the Valencian Community presents significant levels of dangerousness in the context of the Iberian Peninsula, with a high level in the province of Alicante, a moderate level in Valencia and a low level in Castellón [2]. In some points of Alicante have been calculated maximum expected intensities that exceed the IX degree for a return period of 500 years, as is the case of the coastal municipality of Torrevieja. This geophysical reality implies a threat to the southern half of the Valencian Community, which is transformed into a potential risk by being conjugated with socioeconomic elements that are significantly vulnerable.

Despite the high influence that social vulnerability exerts on the construction of risk, the planning and scientific analysis of seismicity have not incorporated a social approach. Traditional seismic risk studies consider the relevance of vulnerability in the seismic risk formula, but the characterization of this concept excludes social elements and includes only 
technical components. This vision is known as a technocratic approach [3], and it is this that dominates the field of seismicity in an unquestionable way [4]. This approach assumes the exposure of human settlements to an uncontrollable nature that produces socio-natural disasters without social causality. By not recognizing the social dimension of the seismic disaster, this vision proposes technical solutions as the only way to face the effects of earthquakes. Social vulnerability, therefore, is completely removed from the analysis while the seismic resistance of the buildings is considered the only possible way to counteract seismic movements. Thus, from the technocratic paradigm, seismic vulnerability is related only to the resilience that material structures present to withstand the force of earthquakes [5]-[7]. This is expressed, for example, in the seismic risk planning of the Valencian Community: "seismic vulnerability is defined as the intrinsic predisposition of a structure, group of structures or entire urban area to suffer damage in the event of a seismic movement of a certain severity" [2]. Therefore, the elements of the socio-demographic structure are isolated from the seismic risk planning. This implies the need to rethink seismic vulnerability to approximate the concept towards a more integrated approach that incorporates a strong social logic [8].

In this way, this paper claims the need to reconfigure the concept of seismic vulnerability and modify the logic and meaning of the risk formula. Taking as reference the physical and social characteristics of the littoral of the province of Alicante, we generate a new formulation of seismic risk through the inclusion of the social factor in the conceptual structure of vulnerability. For this, we elaborate a specific methodological proposal that allows to evaluate in an integral way the physical and social vulnerability of the population groups that are exposed to the seismic risk. From the point of view of risk planning, we consider it absolutely necessary to strengthen the capacity to analyze the social dimension of seismic risk in order to prevent the social impacts produced by earthquakes. In this way, we believe that it is possible to adapt prevention and action measures to real management needs. To do this, we must introduce a long-range vision in the risk analysis, which has a procedural character and allows us to understand the disaster as a socially constructed process where the social structure, at all levels (social class, gender, ethnicity, age, ideology), contributes to the generation of risk status. Thus, applying this perspective of analysis and management, we can achieve an increase in the seismic-social resilience in the province of Alicante, which allows an adequate protection of its population and the social, economic and cultural assets on which it is based.

\section{CASE STUDY: SEISMIC-SOCIAL SITUATION AT THE COAST OF ALICANTE}

The seismicity, despite not being the main natural danger of the last decades in terms of damages provoked, has a high level of potential danger in the province of Alicante, as well as a very significant historical-social transcendence. Therefore, to accurately verify the importance of seismicity in the province of Alicante, it is necessary to contextualize and analyze in an adjusted manner its potential danger, as well as the vulnerability experienced by populations exposed to this natural danger.

\subsection{Seismic hazard}

From a geodynamic point of view, the province of Alicante is one of the most seismically dangerous regions of the Iberian Peninsula. The tectonic dynamics caused by the contact of the African and Eurasian plates around the littoral of the peninsular southeast is responsible for causing an accumulation of geological tension that is released punctually through seismic shocks. 


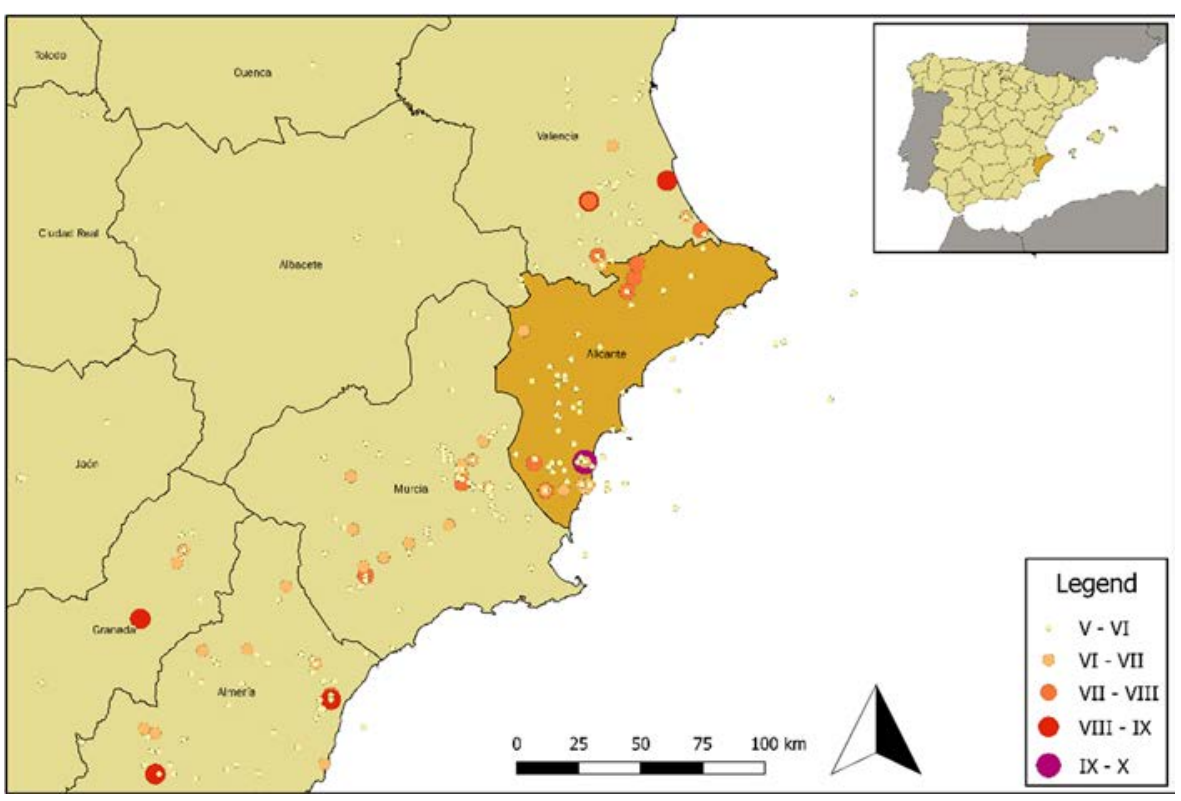

Figure 1: Seismic events of intensity equal to or higher than $\mathrm{V}$ in the peninsular southeast (1940-2017). (Source: Data from the National Geographic Institute (IGN). Own elaboration.)

In general, the magnitude of these episodes presents a low or moderate profile, since the activity model of seismic movements in this area has a high frequency and a low intensity [9]. However, occasionally, larger earthquakes occur, which have sometimes produced significant effects on the population. One of the most emblematic episodes of the seismic history of the province of Alicante is the "Torrevieja earthquake" of March of the year 1829. This earthquake had intensity of IX-X according to the European macroseismic scale (EMS98) and an estimated magnitude from 6.6. This seismic movement produced 389 dead victims, 375 injured and caused material damage so significant that the municipalities of Torrevieja and Guardamar del Segura had to be almost completely rebuilt. On the other hand, in the instrumental period (from 1914), other earthquakes stand out, such as the event of San Miguel de Salinas (Alicante) of 1919, of magnitude 5.2 (Richter scale) and intensity VIIVIII, Onteniente (Valencia) of 1945, of magnitude 4.8 and intensity VII, or Lorca (Murcia) of 2011, of magnitude of 5.1 and intensity VII. This last event produced 9 fatalities and significant economic costs.

According to the Special Plan against Seismic Risk in the Valencia Community, 136 of the 141 municipalities of the province of Alicante $(96 \%)$ are exposed to an expected maximum intensity equal to or higher than VII in a return period of 500 years. Some municipalities of the south of Alicante (Vega Baja) are exposed to maximum expected intensities of up to IX-X, as it is the case of Torrevieja, Elche, Guardamar del Segura, Crevillente or Orihuela.

Thus, from the point of view of the maximum potential risk, seismicity is an absolutely relevant natural hazard in the Valencian Community, especially in the south of the province of Alicante, since it has been proven how throughout history seismic events of high intensity have caused disastrous effects. 
Table 1: Main socio-territorial indicators of the province of Alicante (comparison with other scales). (Source: Data from the National Institute of Statistics (INE), 2016.)

\begin{tabular}{|l|c|c|c|c|}
\hline & Alicante coast & Province & Community & Country \\
\hline Coast municipalities & 19 & $13 \%$ & $4 \%$ & $0.2 \%$ \\
\hline People counted & $1,094,190$ & $59 \%$ & $22 \%$ & $2.35 \%$ \\
\hline Land area $\left(\mathrm{km}^{2}\right)$ & $1,637.6 \mathrm{~km}^{2}$ & $28 \%$ & $7 \%$ & $0.3 \%$ \\
\hline Population density & $668.17 \mathrm{hab} . \mathrm{km}^{2}$ & 334.23 & 215.20 & 91.95 \\
\hline Kilometers of coastline & $244 \mathrm{~km}$ & $100 \%$ & $47 \%$ & $3 \%$ \\
\hline Foreign population & $262,804(24 \%)$ & $77 \%$ & $39 \%$ & $6 \%$ \\
\hline Secondary homes & $34 \%$ & $26 \%$ & $21 \%$ & $14 \%$ \\
\hline Population in services sector & $79 \%$ & $77 \%$ & $72.8 \%$ & $76 \%$ \\
\hline Unemployment rate & $19 \%$ & $20 \%$ & $20 \%$ & $19 \%$ \\
\hline Annual number of visitors & $3,550,000$ & $4,065,000$ & $8,200,000$ & $99,840,000$ \\
\hline Average household income & $20,516 €$ & $20,436 €$ & $21,988 €$ & $26,730 €$ \\
\hline
\end{tabular}

\subsection{Seismic vulnerability}

The coastline of the province of Alicante is a space of risk, due to its natural predisposition to experience extreme phenomena and its socio-demographic vulnerability. The highest vulnerability input at the coast of Alicante has been the socio-economic model implemented since the 1960s [4]. Over time, this model has caused: 1) a high demographic concentration (more than one million people); 2) the hegemony of the tourism-residential sector in the economy; and 3) the socio-economic precariousness of the employed population.

Paradoxically, one of the most dangerous territories in Spain has stimulated the creation of a socio-demographic structure especially vulnerable to natural phenomena experienced in its own physical-geographical space. In relation to this, three basic phenomena inherent in the relationship between Mediterranean coastal space and physical danger (seismicity) can be highlighted.

\subsection{1 "Litoralization of risk"}

Around the coast (mainly the Mediterranean) there is a very high demographic concentration, where at the same time a very high exposure to natural hazards such as floods, earthquakes, droughts or sea storms is experienced [10]. The most attractive areas for population settlements are those where there is precisely a higher physical hazard. This paradox is fundamental to understand how coastal space, in general, presents a higher sensitivity to natural hazards than non-coastal spaces. This difference is more evident in the case of the Mediterranean coast, where the almost exclusive orientation towards the tourism sector produces a differential demographic concentration.

\subsection{2 "Touristification of risk"}

Tourism mostly has an exogenous demand (non-native population). This sector experiences an exposure to an additional risk: the volatility of its assets. Socio-natural disasters are potential destabilizing of tourism assets, since tourists can recognize their exposure to risk and make the decision to mobilize their interest towards other tourist destinations with similar socio-geographical characteristics. This causes the touristification of the risk, which is based on the additional vulnerability that the tourism model experiences for depending on the 
perception and response that its demand may have with natural hazards. The low frequency of earthquakes of high intensity at the Alicante coast allows the invisibility of the seismic risk. However, if an earthquake with a high intensity were produced at the coast of Alicante, a flight of demand could be originated. This would damage the socio-economic structure of the region, since almost $80 \%$ of the employees at the coast depend directly on the tourism sector. Tourism, due to the interdependent relationships of its assets, is a sector with additional exposure to risk.

\subsection{3 "Residentialization of risk"}

The Alicante coast, since the early nineties, has experienced an intense process of urban residentialism. With this has been implemented a model of use of the territory and natural resources visibly unsustainable and vulnerable to natural hazard [11]. Residential tourism has not stimulated the tourist assets associated with the socio-environmental structure of the Alicante coast, but, contrary, has used them as an attraction to enhance the exploitation of the land and ensure the sale success of the homes built [12]. This model, more similar to the real estate sector than the tourism sector, has led to the production of a socio-urban environment composed of multiple elements that contribute to increasing the vulnerability of municipalities, as is the case:

- Increase in foreign population, with linguistic and cultural barriers to achieve an adequate adaptation to the local socio-territorial culture.

- Increase in the elderly population.

- Demographic instability and economic seasonality.

- High and unsustainable consumption of natural resources, basically land and water (lax and extensive territorial model).

- Creation of a disorganized, accelerated and unplanned socio-urban model.

- Occupation of spaces of high landscape value, but isolated and with higher exposure to extreme natural phenomena.

In short, the socio-economic model of the Alicante coast has been characterized by the production of new patterns and elements of socio-natural vulnerability, based on the inadequate use of the territory and the configuration of a fragile and unstable population structure with a lot of socio-environmental externalities. All this, in combination with the physical danger described, projects an extraordinary seismic risk at the Alicante coast.

\section{TOWARDS AN INTEGRAL ASSESSMENT OF SEISMIC VULNERABILITY}

\subsection{Concept of social vulnerability (ontological aspects)}

Vulnerability, despite presenting a long path within the scientific production associated with socio-natural disasters, is not yet endowed with a uniform and solid theoreticalmethodological conceptualization [13]. Vulnerability is a polysemic concept [14], with a great conceptual breadth and an extensive analytical space, which, due to its high scope, is exposed to a heterogeneous conceptualization of its ontology [15]. In fact, there is no clear boundary that separates vulnerability from other concepts, which are not completely equidistant but may overlap in some conceptual dimensions. This is the case, for example, of the concepts of poverty or marginality. Unlike these, vulnerability presents adaptive potential [16], while the others denote a strong social disadvantage. Vulnerability allows introducing the possibility of offering a response to environmental threats through assets and adaptive strategies [17]. However, the vulnerability approach reveals the unequal distribution, access 
and occupation of resources associated with the social structure [18]. Its object of study, therefore, is closely related to social inequality in socio-natural disasters [19].

In this paper we have followed the definition of vulnerability proposed by Wisner et al. These authors understand vulnerability as "the characteristics of a person or group in terms of their capacity to anticipate, cope with, resist and recover from the impact of a natural hazard" [20]. It is a neutral definition, which disables the exclusively negative meaning of the concept and offers the possibility of a favorable adaptation to the threat. This definition unites the negative and positive orientation of vulnerability, discarding the distinction between vulnerability (negative sense) and resilience (positive sense) as two independent concepts proposed by several authors [21]-[23].

Thus, from the neutral concept of vulnerability, in this paper we distinguish, first, the category "resilience", which describes a situation of positive vulnerability through which an individual, group or society experiences the availability of adequate assets and strategies to achieve a favorable adaptation. Its opposite pole is "desilience", which reflects an opposite situation. This refers to a situation of negative vulnerability through which an individual, group or society does not have adequate assets and strategies to achieve a favorable adaptation to environmental threats. The balance between weaknesses and strengths (interaction between assets and strategies), in relation to the specific adaptive demands of a specific threat, is precisely what determines the resilient or desilient sense of an entity.

In summary, the vulnerability approach represents the need to construct a complex meaning of risk and to give a main role to the elements related to the social structure in which a natural threat is manifested. Essentially, this vision recognizes that the social structure, as a reflection of the unequal distribution, access and occupation of resources, processes a differential production and distribution of risk.

\subsection{Operationalization of seismic vulnerability}

Generally, if we consider that vulnerability is related to the relationship of adequacy established between the assets and strategies and the content and form of the impacts of a threat, the seismic vulnerability would refer to the specific adjustment of resources to counteract the impacts of the seismic movements.

Different studies of socio-natural risks indicate the need to divide the concept of vulnerability into different dimensions or levels to carry out its operationalization [24]-[26]. A large number of dimensions can be distinguished, but all of them are usually associated with three or four large dimensional blocks. Wilches-Chaux [27], for example, analyzes 9 dimensions: physical, environmental, economic, social, political, educational, institutional, cultural and ideological. However, in order to simplify the operationalization of the concept of vulnerability and facilitate its measurement, as well as the high level of homogeneity of the components, we consider it appropriate to reduce the analysis to four dimensions. Therefore, the dimensions that we use to evaluate seismic vulnerability in an integral way are:

- Material dimension: physical aspects that give space and material support to human settlements. We refer to the seismic resistance of the buildings, as well as to the adaptive functionality and the harmfulness of the material infrastructure of a municipality.

- Organizational dimension: aspects related to the disposition and organizational quality presented by the population, the institutions that have the power to make decisions and the operational resources. We refer to the organizational assets that enable the articulation of adequate prevention and action systems. 
- Individual dimension: physical and cognitive abilities that individuals have to act in an appropriate manner at the time of occurrence of a seismic movement, as well as the level of awareness that the population has about their exposure to risk.

- Structural dimension: aspects related to the social structure that influence the sizing of the impacts produced by an earthquake. Elements with the ability to act in the subsequent phase to the seismic movement, determining the quality of the long-term consequences.

Depending on the quality, access, availability and social distribution of these assets, as well as on the interactive effectiveness that all of them present for the configuration of adaptive strategies, the vulnerability will find its resilient or desilient meaning (see Section 3.1).

On the other hand, the optimal analysis unit that should be used in this methodology is the municipality. The data that must be collected is at the municipal level. It is a level of work that presents a sufficiently adequate level of information accessibility. In addition, this scale allows to have a relevant level of homogeneity and analytical representation. Also, from the point of view of seismic risk planning, it is convenient to work with this unit of analysis, since the development of management plans is the responsibility of the municipal administrations.

\subsection{Assessment method}

Once the scale of work and the dimensional characters of vulnerability have been identified, we have generated a list of indicators to carry out the integral evaluation of seismic vulnerability. These indicators, depending on their adaptive quality, determine the meaning of the vulnerability of a specific municipality, as well as its specific degree. As can be seen in Table 2, we have proposed, in addition to the general indicators, an approximate system to carry out the measurement of seismic vulnerability. Therefore, we have created categories that guide the evaluation of each of the proposed indicators in a specific way. It is a way to homogenize the evaluation and achieve equidistance between the municipalities evaluated. The measurement system is based on ordinal categories with a numerical equivalence. This allows us to perform a quantitative assessment of seismic vulnerability.

The process of accessing information related to each of the indicators is basically secondary. Most of the indicators proposed are data available in official databases. However, some indicators require primary information. Therefore, it is necessary to carry out a qualitative study about the social perception of seismic risk. In addition, this study can be useful to complement and enrich the proposed methodology, which is fundamentally quantitative. If we want to understand risk as a socially constructed process with deep causes and latent inertias, it is absolutely necessary to incorporate qualitative analysis tools in the structure of this methodology. A qualitative interpretation of vulnerability factors is an analytical strategy that must accompany the final index.

The measurement system presents a remarkable methodological simplicity. The technique consists of adding the scores obtained and dividing the result by the maximum possible result, in this case 45 . The numerical equivalence of the ordinal categories allows, precisely, to obtain a final index. The scale of oscillation of the index covers a spectrum of meaning ranging from 0 , which would be equivalent to the maximum possible negative vulnerability or desilience, up to 1, equivalent to the maximum possible resilience or positive vulnerability.

The formula to calculate the seismic vulnerability index is:

$$
{ }_{\mathrm{sv}} \mathrm{I}=\frac{\Sigma S}{C \cdot V \cdot N}
$$




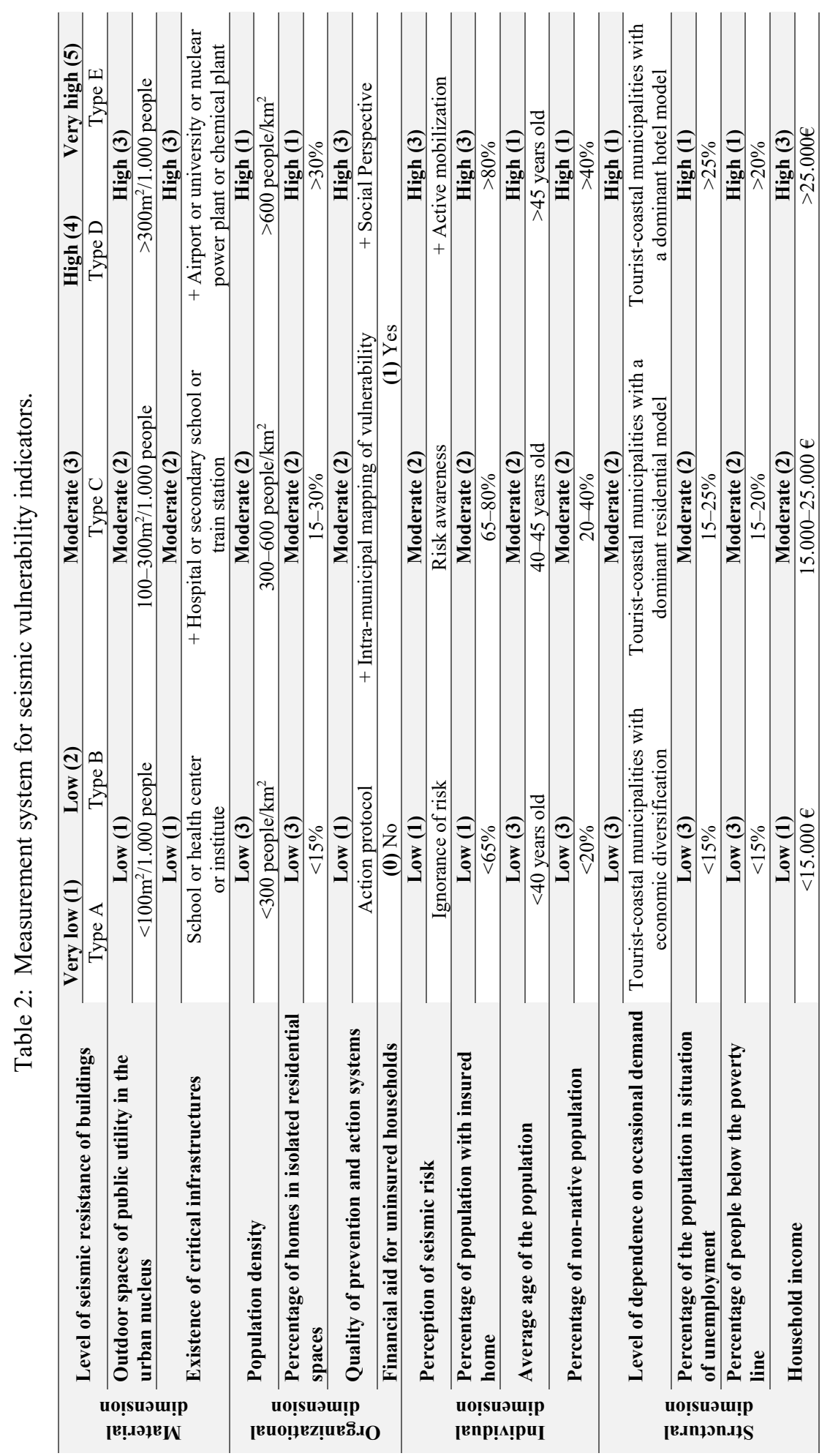


where ${ }_{\mathrm{sv}} \mathrm{I}=$ seismic vulnerability index; S: scores; C: number of categories; V: number of variables; and N: number of case studies.

Due to this logic, not all the ordinal categories (low, medium and high) associated with the indicators present the same numerical translation. For example, in the case of population density, the "low" category has the highest numerical score (3), since a low density implies a lower population vulnerability in the face of a seismic movement. The opposite occurs with household income, where the maximum numerical score corresponds to the "high" ordinal category, which is the most appropriate level for a household to adapt successfully to the effects of an earthquake.

On the other hand, with this proposal we do not want to discredit the importance of architectural seismic resistance, but to increase the spectrum of variables including social components. We believe that the seismic resistance of the buildings presents a vital importance for the confrontation of the effects of an earthquake, mainly during the activity of the event. The seismic resistance of buildings is a main variable to determine the number of fatalities and injuries. Therefore, this variable has to be weighted so that it has a higher influence than the others in the calculation process of the final seismic vulnerability index. The weighting factors associated with each level of physical resistance of buildings are shown in Table 3.

This index synthesizes the quantitative version of the reality of the study, and for this reason is exposed to an irremediable level of imprecision. However, from the point of view of planning, the quantitative representation of reality also presents strengths, since it involves interpretative practicality and analytical parsimony. This allows the agility of the decisionmaking process. However, this index should be complemented by a parallel qualitative reading, which provides an explanatory diagnosis of the seismic vulnerability of a municipality. In this way, if both measurement and analysis strategies are combined, the decision makers will be able to identify more clearly the dimension of the problems, as well as the specific solutions to combat them.

\section{CONCLUSIONS}

The analysis and evaluation of seismic vulnerability present a lack of social elements and a procedural vision associated with the seismic risk construction process. The planning of this risk is clearly dominated by the technocratic-quantitative paradigm. This approach does not recognize the social dimension of natural disasters, so it proposes technical solutions to mitigate the negative consequences of seismic movements. However, in this paper we have shown an intersection between a high seismic hazard and a situation of highly negative seismic vulnerability in the littoral of the province of Alicante, which must be addressed through new instruments of analysis, evaluation and management.

Table 3: Weighting factors of the categories of seismic resistance.

\begin{tabular}{|c|c|}
\hline Category of seismic resistance & Weighting factor \\
\hline Type A & 0.8 \\
\hline Type B & 0.9 \\
\hline Type C & 1 (not ponderate) \\
\hline Type D & 1.1 \\
\hline Type E & 1.2 \\
\hline
\end{tabular}


The use of a social approach and the construction of a specific methodology that adapts its epistemological logic to execute it is a necessary and useful strategy to change the management paradigm of this natural danger. This paper proposes, therefore, to incorporate the social factor in the concept of seismic vulnerability to achieve an integrated risk assessment. The purpose of this methodology is to achieve the design of strategies and mechanisms to increase the security of the population and the strength of the socio-economic and cultural assets of society and territory.

\section{REFERENCES}

[1] Olcina, J., Catástrofes en la Comunitat Valenciana. ¿Existe un riesgo real? I Jornadas ASACAMV, 20 Jan, Colegio de Médicos de Alicante: Alicante, 2011.

[2] PERSCV, Plan Especial frente al Riesgo Sísmico en la Comunitat Valenciana. Decreto 44/2011. Conselleria de Governació y justiciar, 2011.

[3] Hewitt, K., Daños ocultos y riesgos encubiertos: haciendo visible el espacio social de los desastres. Desastres: modelo para armar. Colección de piezas de un rompecabezas social, La Red, Lima, pp. 11-29, 1996.

[4] Aledo, A. \& Sulaiman, S., La incuestionabilidad del riesgo. Ambiente \& Sociedade, 17(4), pp. 9-16, 2014.

[5] Barona, D.M., Vulnerabilidad sísmica del centro histórico de Sangolquí. Bachelor's thesis, SANGOLQUÍ/ESPE/2010, 2010.

[6] Sandi, H., Vulnerability and risk analysis for individual structures and systems. Proceedings of the 8th European Conference on Earthquake Engineering, pp. 11-60, 1986.

[7] UNESCO, Terremotos: evaluación y mitigación de su peligrosidad, Blume: Barcelona, 1980.

[8] Cardona, O., La necesidad de repensar de manera holística los conceptos de vulnerabilidad y riesgo. Una crítica y una revisión necesaria para la gestión. Proceedings of International Work-Conference on Vulnerability in Disaster Theory and Practice, Disaster Studies of Wageningen University and Research Centre: Wageningen, Holanda, 2001.

[9] Caturla, J.J. \& Palacios, S.M., Sismicidad y riesgo sísmico en la CAV, Editorial Club Universitario: Alicante, 2001.

[10] Olcina, J., Cambio climático y riesgos climáticos en España. Investigaciones Geográficas, 49, pp. 197-220, 2009.

[11] Aledo, A. et al., La insostenibilidad del turismo residencial. Antropología y Turismo, D. Lagunas (Coord.), Plaza y Valdés: México, 2007.

[12] Aledo, A., De la tierra al suelo: la transformación del paisaje y el nuevo turismo residencial. Arbor: Ciencia, Pensamiento y Cultura, 729, pp. 99-113, 2008.

[13] Bell, S. \& Morse, S., Sustainability Indicators: Measuring the Immeasurable? Earthscan: London, 2008.

[14] Aledo, A., Turismo residencial y vulnerabilidad en el interior del Levante español. Pasos: Turismo residencial y gentrificación rural, 16, pp. 37-59, 2016.

[15] Méndez, R., Abad, L. \& Echaves, C., Atlas de la crisis: impactos socioeconómicos y territoriales vulnerables en España, Tirant Humanidades: Valencia, 2015.

[16] Sánchez-González, D. \& Egea-Jiménez, C., Enfoque de vulnerabilidad social para investigar las desventajas socioambientales: Su aplicación en el estudio de los adultos mayores. Papeles de población, 17(69), pp. 151-185, 2011.

[17] Katzman, R., Activos y estructuras de oportunidades: estudios sobre las raíces de la vulnerabilidad social en Uruguay, CEPAL: Montevideo, 1999. 
[18] García-Acosta, V., El riesgo como construcción social y la construcción social de riesgos. Desacatos, 19, pp. 11-24, 2005.

[19] Pizarro, R., La vulnerabilidad social y sus desafíos: una mirada desde América Latina, CEPAL, 2001.

[20] Wisner, B., Blaikie, P., Cannon, T. \& Davis, I., At Risk: Natural Hazards, People's Vulnerability and Disasters, Routledge: London, 2004.

[21] Fergusson, D. et al., Vulnerability and resiliency to suicidal behaviours in young people. Psychological Medicine, 33(1), pp. 61-73, 2003.

[22] Becoña, E., Resiliencia: definición, características y utilidad del concepto. Revista de Psicopatología y Psicología Clínica, 11(3), pp. 125-146, 2006.

[23] De Villotta, I., Goy, J.L., Zazo, C., Barrela, I. \& Pedraza, J., Landscape analysis based on environmental units and visual areas. The use of geomorphological units as a basic framework. La Vall de Gallinera, Alicante. Geomorphological and Environmental Impact Assessment, eds M. Marchetti \& V. Rivas, AA Balkema Publishers, pp. 133153, 2001.

[24] Chardon, A., Un enfoque geográfico de la vulnerabilidad en zonas urbanas expuestas a amenazas naturales: el ejemplo andino de Manizales, Colombia, Universidad Nacional de Colombia: Sede Manizales, 2002.

[25] Anderson, M. \& Woodrow, P., Rising from the Ashes: Development Strategies in Times of Disaster, Westview Press: Boulder, CO, 1989.

[26] Cardona, O., Estimación holística del riesgo sísmico utilizando sistemas dinámicos complejos, Universitat Politècnica de Catalunya, 2001.

[27] Wilches-Chaux, G., Desastres, ecologismo y formación professional, Servicio Nacional de Aprendizaje (SENA): Popayán, Colombia, 1989. 